\title{
An Investigation on Laser Welding Parameters on the Strength of TRIP Steel
}

\author{
Khot Rahul S1 - T. Venkateshwara Rao ${ }^{2}$ - Harshad Natu ${ }^{3}-$ \\ H.N. Girish ${ }^{4}$ - Tadashi Ishigaki ${ }^{5}$ - Puttaswamy Madhusudan6,7,* \\ ${ }^{1} \mathrm{~K}$ L University, Mechanical Department, India \\ 2 DBS Institute of Technology, Mechanical Department, India \\ ${ }^{3}$ Magod Fusion Laser Welding System, India \\ ${ }^{4}$ University of Mysore, Department of Earth Science, India \\ 5 Tottori University, Faculty of Engineering, Japan \\ ${ }^{6}$ Environmental Engineering and Management Research Group, Ton Duc Thang University, Ho Chi Minh City, Vietnam \\ 7 Faculty of Environment and Labour Safety, Ton Duc Thang University, Ho Chi Minh City, Vietnam
}

The energy required for joining steel segments by using laser welding is relatively very low compared with arc welding, gas welding, or any other conventional welding techniques. Moreover, the rapid cooling may create a significant effect on different regions, such as the fusion zone (FZ), heat affected zone (HAZ), and base metal (BM), and in turn affect different parameters. In this study, the characteristics of the laser-welded joint were investigated by varying laser power, welding velocity and incident angle, and tensile strength. In our, experiments. the microhardness was increased by varying the power of laser welding. The strength of the joint was increased to $549 \mathrm{MPa}$ with $2200 \mathrm{~W}$ high power, $30 \mathrm{~mm} / \mathrm{s}$ velocity, and $80^{\circ}$ laser incident angle. By increasing the power and velocity of the laser, the welding gun strength was improved; conversely, the angle of laser incident on the welding location decreased while its strength was increased.

Keywords: TRIP steel, laser welding, Nd:YAG laser, mechanical strength, microhardness

\section{Highlights}

- The effect of laser power, laser welding velocity, and incident angle were examined, which revealed enhanced mechanical properties.

- $\quad$ Microhardness was increased to 549 MPa by increasing the power of laser welding.

- Welding strength is improved by varying the power and velocity.

- $\quad$ Varying the laser incident angle $9.62 \%$ tensile strength and $67 \%$ deformation was achieved.

\section{INTRODUCTION}

Throughout the world fuel consumption is significantly increasing day by day, so to meet the increasing demand, energy costs have been considerably increasing [1] to [3]. In this regard, to reduce fuel consumption, automobile industries are considering cutting down the weight of vehicles to improve their overall performance and fuel economy [4] to [6]. The continuous development in new grades of steel from global steel industries, with the required features and ever-increasing strength, has remarkably improved the demand for advanced high-strength steels (AHSS) in the market [7]. The AHSS are complicated materials with precise chemical content and different phase, resulting from accurately restrained heating and cooling mechanisms [8] and [9]. Recently, a variety of strengthening methods have been developed to enhance the strength, flexibility, persistence, and lethargy properties in steel [10]. However, at present, tensile strengths as short of $440 \mathrm{MPa}$, are observed in several AHSS phases and hence, there is a need to utilize force as a threshold to enhance the AHSS steel. At present, it is recommended that an additional constituent of the family of AHSS-termed dual-phase (DP) steel is delicate at the sub-critical heat-damaged zone due to restraining of the martensite [11] to [18].

Furthermore, the transformation induced plasticity (TRIP) steels with enormous strength and ductility properties has emerged as a new generation material to replace AHSS and thus to meet the requirements of automobile industries [19]. The base metal microstructure of TRIP steel is mainly constituted with a ferrite matrix along with trace amounts of martensite, bainite, and confined austenite alloys [20]. In plastic bucklings, austenite is converted into martensite to achieve superior extension steels with their excellent combination of strength and ductility [21] and [22].

Henceforth, all the engineering applications which had been used earlier consist of straight lined joint over the levelled surface. The motivation for such variation is that the exceptional characteristics of the laser joint with the close connection between the depth and width of the joint are slightly distorted on the constituent, which can only be achieved 
through high welding acceleration [23]. Consequently, regarding potential industrial applications of the laser, the variations provide additional applications for laser beam welding in automobile bodies. The high-power concentration of a persistent laser beam offers many advantages over conventional joining techniques for rapid, recurring, high-quality welding of long, straight seams, and axisymmetric mechanism [24] and [25]. Furthermore, the multi-kilowatt neodymium yttrium aluminium garnet (Nd:YAG) lasers are also accessible, with the resilience of fibre optic beam distribution, and their use in the field of complex three-dimensional conversion is increasing [26]. Here, it must be mentioned that the Nd:YAG laser is a substitute beam source, which forms reasonable arrangement solutions for the welding of thin metal sheet production. Nevertheless, it also has defects in geometry, adhering gaps, or inhomogeneities in the material or its exterior that are vulnerable to the charge or generated by previous construction operations [27]. Yang et al. [28] illustrated that in the double-adjoin laser beam welding, the constraint such as incident beam position, beam angle, and beam dissolution distance greatly influence the metallurgical quality of the T-joints.

The laser beam welding (LBW) technique is one of the advanced automated techniques used in recent times. Primarily, there are two main LBW modes: the profound infiltration (or keyhole) welding method and the thermal conduction welding method. Further, the differences in laser wavelength, beam quality, and power induced are accountable for diverse welding development and their outcome [29]. Also, the ultimate tensile strength (UTS) and average yield strength (YS) of the soldered joint were not deprived related to base metal despite their existing softened zone. This claim has been further specified by Rizzi et al. [30] who extensively researched laser joining of TRIP, DP, and martensitic steels

Furthermore, Xia et al. [18] engaged laser welding on the Al-alloyed TRIP steel and observed that ferrite was solitary of the prevalent time in the fusion zone due to the ferrite-balance possessions of Al. Nevertheless, related to previous welding procedures, such as arc welding, solid-state welding, induction welding, and friction stir welding, less heat is coupled into the workpiece during laser welding, which arises in a heat-affected zone with low deformation [31] to [34]. To produce multiple phases in steels, with retained austenite (RA), martensite $(\mathrm{M})$, ferrite $(\mathrm{F})$, and tempered martensite (TM), a new heat treatment process was proposed and implemented [35] to [39].
In this manuscript, the laser welding of TRIP steel was explored by the laser beam welding process utilizing a high-quality Nd:YAG laser beam. The characterization of material was investigated, and the influence of different welding conditions, including the angle of the weld, the velocity of laser welding, and power of beam on the strength of the joint, was investigated. Furthermore, the microstructure, tensile behaviour, microhardness of TRIP laser-welded sheets, and their behaviour on the heat-affected zone (HAZ) and fusion zone (FZ) were examined and discussed.

\section{MATERIALS AND METHODS}

The TRIP steels under investigation were supplied by Nextgen Steels and Alloys Company in the form of a cold-drawn sheet with a thickness of $2 \mathrm{~mm}$. The weld was performed on the transverse direction of the length of the specimen, which is prepared as per the ASTM E8/E8M [40] standards with the desired length. The laser welding setup with a schematic diagram along with the chemical compositions and mechanical properties of as-prepared materials can be obtained from our recent publication [41].

The TRIP steel sheets were welded using a $\mathrm{Nd}$ : YAG laser power welding system. The GmbH 56218 series laser machine (Karlich Germany) with threephase $50 \mathrm{~Hz}$ to $60 \mathrm{~Hz}$ frequency, maximum power of $13.5 \mathrm{~kW}$, and a $400 \mathrm{~V}$ to $480 \mathrm{~V} \pm 10 \%$ power source and $900 \mathrm{~nm}$ to $1300 \mathrm{~nm}$ wavelength laser was used for welding. Furthermore, the butt welding was performed employing an $\mathrm{ABB}$ six-axis robot arm, which efficiently handles the welding process with a minimum scrap of $6 \mathrm{~kg}$ payload carrying capacity. The welding velocity was kept at $25 \mathrm{~mm} / \mathrm{s}$ with a power of $2000 \mathrm{~W}$, the beam diameter of $0.6 \mathrm{~mm}$, and a focal distance of $113 \mathrm{~m}$. The welding angle is considered to be $90^{\circ}$ for the working table. The experimental setup and laser welding performance are shown in Fig. 1. In a typical experimental section, three different input variables were employed with different permutations and combinations. A sequence numbering system was specified for each sample according to the preparation conditions. The first number specifies the power used in the experiment, while the second number specifies the velocity, and the third number specifies the angle of the laser incident applied in the experiment. As shown in Fig. 2, the first number 1 indicates a laser beam of $1800 \mathrm{~W}$ power, while the second number 1 indicates $25 \mathrm{~mm} / \mathrm{s}$ velocity used and the last number 1 indicates the laser incident angle employed during the experimental setup. Furthermore, the corresponding 
input parameters are tabulated in Table 1. A total of 27 specimens with $\left(3^{3}\right)$ diagonal array was investigated for different welding parameters, such as the angle of the weld, the velocity of laser welding, and power of beam on strength of the joint.
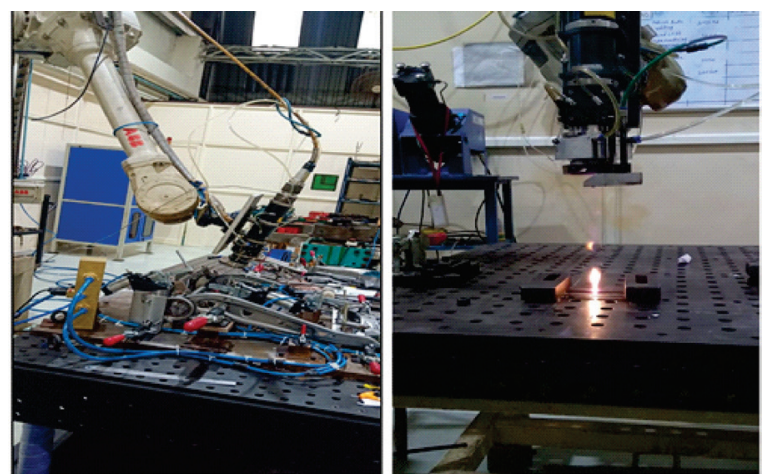

Fig. 1. Laser welding setup with performing welding of plates

The as-prepared samples were assessed for microstructure at FZ, HAZ, and base metal (BM), along the transverse cross-section of weldments. The cross-sections were mounted in black Bakelite power and heated at $70{ }^{\circ} \mathrm{C}$ followed by polishing using different silicon carbide grit paper. After polishing, the samples were further polished with a lapping machine using alumina powder with water. The polished samples were dipped in the $5 \%$ nital solution and $95 \%$ of methanol solution and used for further characterization. The microstructure deformation and ultimate tensile test were measured using a universal testing machine (UTM), manufactured by SAR Testing Systems with Model No. STS 248 with an operating velocity of $5 \mathrm{~mm} / \mathrm{min}$ and the precision of the machine is $\pm 1 \%$. The thermal image was recorded using a Testo $875 \mathrm{i}$ thermal imaging camera.

Table 1. Levels of input parameters

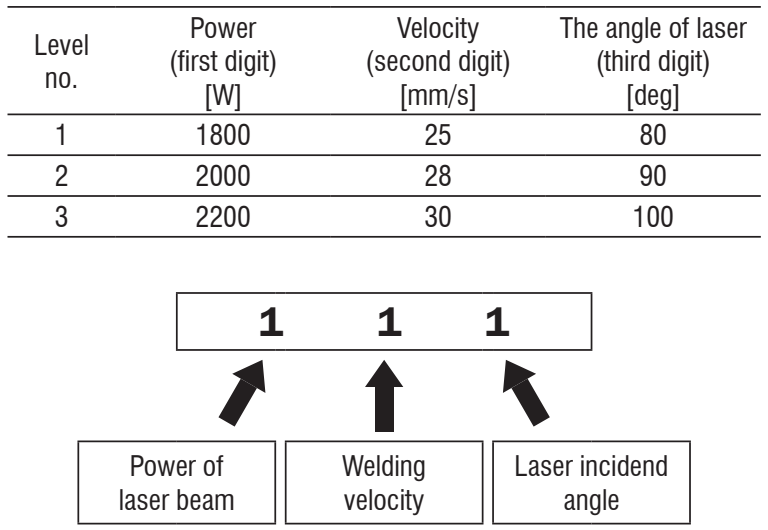

Fig. 2. A nomenclature system for sample numbering

\section{RESULTS AND DISCUSSION}

\subsection{Microstructure Analysis}

The microstructure of TRIP steel is composed of ferrite matrix along with varied fractions of bainite,
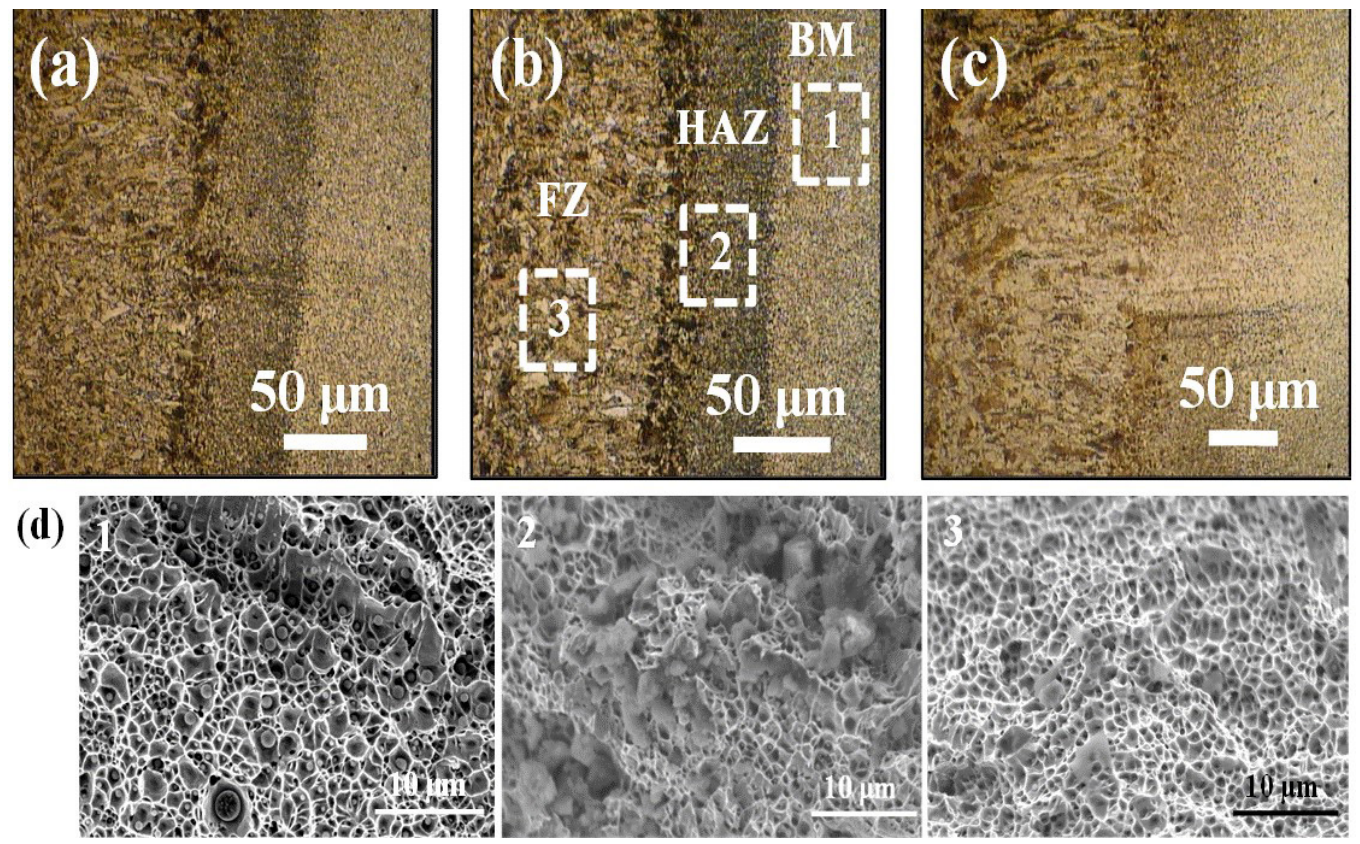

Fig. 3. The microstructure of joint with different specimen a) 311 , b) 322, c) 333 and d) FESEM images of the white rectangles in (b) 
martensite, and retained austenite. The microstructure of samples 311, 322, and 333 were measured using an optical microscope, Reichert (Austria) and the results are illustrated in Fig. 3. From Fig. 3a, it could be observed that the microstructures predominantly consist of ferrite as base metal throughout the samples and in the welding section, a segregated form of ferrite was observed along with some amount of bainite at weld imperfections with a significant absence of fractures. Furthermore, the measurement of FZ and HAZ zone was calculated on butt joints at three different locations: at the radiation exposure side, a centre of the weld, and the weld root region. As seen in Fig. 3b, the steel structure is divided into three distinct phases: FZ, HAZ, and BM marked as 1,2 , and 3 , respectively. The boundary between the $\mathrm{BM} / \mathrm{HAZ}$ and $\mathrm{FZ} / \mathrm{HAZ}$ is very well demarcated with colour contrast and grain size boundary difference. Moreover, to understand the surface morphology of the three distinct phases, in Fig. 3b, field emission scanning electron microscopy (FESEM) was conducted, and the results are illustrated in Fig. 3d. From the FESEM images, it can be observed that the grain size distribution in HAZ is quite uniform with rounded smaller voids and less porous, whereas it should be noted that the BM and FZ displayed higher proportion and larger voids than that of the HAZ section.

\subsection{Microhardness Analysis}

The microhardness was measured using the Everone/ MH-3 testing machine with $1000 \mathrm{gf}$ load and $10 \mathrm{~s}$ dwelling time as a standard. The tests were performed at a distance of $0.5 \mathrm{~mm}$ from the top surface of the upper plate. When the power was kept at $2200 \mathrm{~W}$, and other parameters are reserved at low conditions, it showed 185 HV1.0/10 hardness, when the other parameters were moved to its higher level, i.e., 30 $\mathrm{mm} / \mathrm{s}$ velocity and $100^{\circ}$ laser incident angle, then the hardness increased to $195 \mathrm{HV1.0/10.} \mathrm{Nevertheless,}$ when the power was kept at $1800 \mathrm{~W}$, the hardness value significantly reduced to $110 \mathrm{HV} 1.0 / 10$ for $90^{\circ}$ angle and $116 \mathrm{HV} 1.0 / 10$ for $100^{\circ}$. It is interesting to observe that when the velocity of the laser beam and laser incident angle were kept constant (i.e., 28 $\mathrm{mm} / \mathrm{s}$, and $90^{\circ}$ incident angles with $2000 \mathrm{~W}$ power), the microhardness value reached $168 \mathrm{HV1.0/10}$. The corresponding microhardness value concerning the sample condition is shown in Table 2. From the above results, it is obvious that the microhardness value considerably changed as the power of laser welding, laser incident angle, and laser welding velocity was varied.

Table 2. Microhardness values changing as per the sample condition is different

\begin{tabular}{cc}
\hline Sample conditions & Hardness [HV1.0/10] \\
\hline 311 & 186 \\
\hline 333 & 195 \\
\hline 222 & 168 \\
\hline 323 & 172 \\
\hline 112 & 110 \\
\hline 113 & 116 \\
\hline 213 & 184 \\
\hline 322 & 180 \\
\hline 232 & 180 \\
\hline 331 & 176
\end{tabular}

\subsection{Tensile Strength Analysis}

The optimum welding velocity for the prevention of porosity and crumple of the keyhole in weld samples was adopted from the previous publication results [35]. These values are used as a standard to attain the essential weld properties include strengthening at the reverse side of the weld, least allocation in micro-hardness, and homogeneous microstructure. Furthermore, during the joining process, it was observed that the power density for each procedure could be determined from the subsequent equation.

$$
H I=\eta \frac{P_{\text {Laser }}}{S\left(\frac{\pi D^{2}}{4}\right)},
$$

where $P_{\text {Laser }}$ is the laser power [W], $\eta$ is the competence of the laser for low-carbon steel that was measured to be 0.6 , while, $S$ is the scan velocity [s], $D$ is the diameter of the laser spot $(0.4 \mathrm{~mm})$.

\subsubsection{Velocity}

During the experimental condition, three different velocities are considered, as discussed previously. As shown in Fig. 4, when velocity is kept constant at $1800 \mathrm{~W}$ and indecent angle maintained at $80^{\circ}$ and by altering the velocity, the change in maximum load withstand capacity, total strength, and deformations were observed. By altering the velocity load-carrying capacity, an increase in tensile strength with increased elongation was observed. Furthermore, by increasing the velocity from $25 \mathrm{~mm} / \mathrm{s}$ to $30 \mathrm{~mm} / \mathrm{s}$ and because of high velocity and rapid cooling of steel weld, 
a)

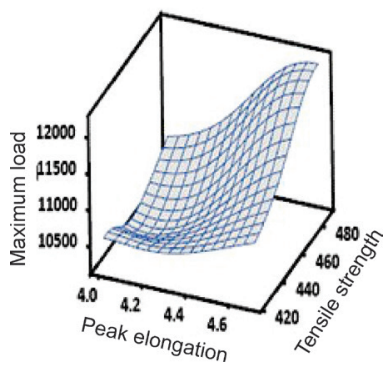

b)

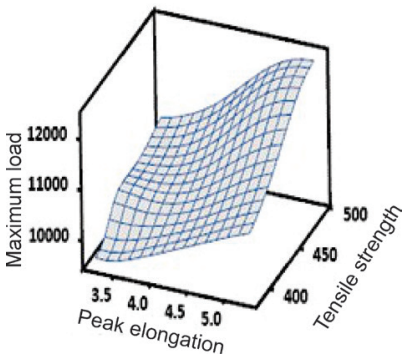

c)

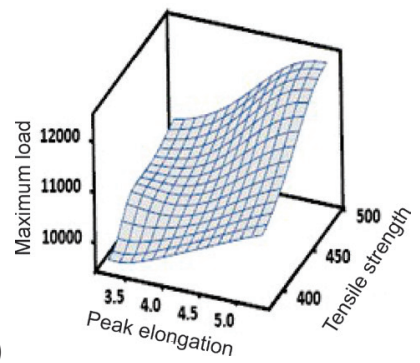

Fig. 4. The surface plot of maximum load vs.tensile strength and peak elongation for keeping laser power and angle of the weld is constant; a) velocity $25 \mathrm{~mm} / \mathrm{s}$, b) velocity $28 \mathrm{~mm} / \mathrm{s}$, and c) velocity $30 \mathrm{~mm} / \mathrm{s}$ (aspect ratio $5: 4$ )

the nature of elongation curve changed from a limp shape to a stiff shape, indicating an increase of tensile strength in as-prepared steel weld.

\subsubsection{Laser Power}

The power of the welding gun is kept constant at 2.2 $\mathrm{kW}$ and the variation was performed in terms of weld velocity and angle of laser incident. The velocities are $25 \mathrm{~mm} / \mathrm{s}, 28 \mathrm{~mm} / \mathrm{s}$, and $30 \mathrm{~mm} / \mathrm{s}$, and the angle of the laser incident is changed from $80^{\circ}, 90^{\circ}$, and $100^{\circ}$. As shown in Fig. 5, it could be observed that at $2200 \mathrm{~W}$ power and $25 \mathrm{~mm} / \mathrm{s}$ velocity the tensile strength was decreased with an increase in laser incident angle from $80^{\circ}$ to $100^{\circ}$. Furthermore, the deformation changed from $5.5 \mathrm{~mm}$ to $5.1 \mathrm{~mm}$ with an increase in incident angle. Interestingly, a minor increase in tensile strength was observed when the incident angle was changed from $90^{\circ}$ to $100^{\circ}$. Also, as shown in Table 3, the tensile strength increased to $500.98 \mathrm{MPa}$ for a joint prepared at $2.2 \mathrm{~kW}$ power, $25 \mathrm{~mm} / \mathrm{s}$ velocity, and $80^{\circ}$ incident angle. As the velocity was changed from 25 $\mathrm{mm} / \mathrm{s}$ to $28 \mathrm{~mm} / \mathrm{s}$, the tensile strength was increased to $531.55 \mathrm{MPa}$; furthermore, when the incident angle was set to $100^{\circ}$ the tensile strength enhanced to 549.19 $\mathrm{MPa}$. When the velocity was increased from $25 \mathrm{~mm} / \mathrm{s}$ to $28 \mathrm{~mm} / \mathrm{s}$ and fixing the laser incident angle to $80^{\circ}$, the strength of the steel was improved, in contrast, a)

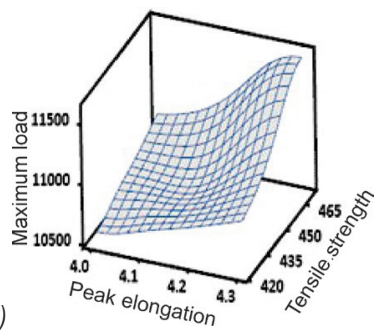

b)

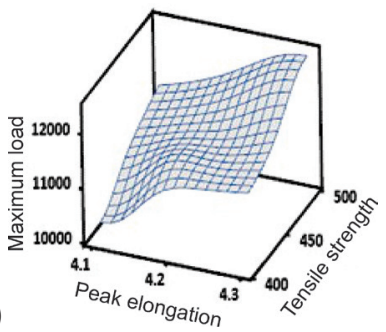

c)

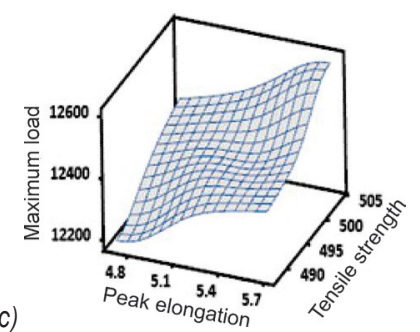

Fig. 5. The surface plot of maximum load vs.tensile strength and peak elongation for keeping laser beam velocity and angle of the weld are constant; a) power $1800 \mathrm{~W}$, b) $2000 \mathrm{~W}$ and c) $2200 \mathrm{~W}$ (aspect ratio 5:4).

Table 3. Variations in tensile strength by changing the velocity of the laser beam

\begin{tabular}{ccccccc}
\hline Serial no. & Sample number & $\begin{array}{c}\text { Maximum load } \\
{[\mathrm{N}]}\end{array}$ & $\begin{array}{c}\text { Peak elongation } \\
{[\mathrm{mm}]}\end{array}$ & $\begin{array}{c}\text { Break load } \\
{[\mathrm{N}]}\end{array}$ & $\begin{array}{c}\text { Break elongation } \\
{[\mathrm{mm}]}\end{array}$ & $\begin{array}{c}\text { Tensile strength } \\
{\left[\mathrm{N} / \mathrm{mm}^{2}\right]}\end{array}$ \\
\hline 1 & 311 & $12,524.4$ & 4.8 & $10,887.8$ & 5.5 & 500.98 \\
\hline 2 & 312 & $12,191.2$ & 4.7 & $11,064.2$ & 5.4 & 487.65 \\
\hline 3 & 313 & $12,299.0$ & 4.8 & $12,034.4$ & 5.1 & 491.96 \\
\hline 4 & 321 & $13,897.6$ & 8.5 & $12,289.2$ & 8.8 & 531.55 \\
\hline 5 & 322 & $12,376.6$ & 5.3 & $11,260.2$ & 5.9 & 494.71 \\
\hline 6 & 323 & $10,917.2$ & 4.5 & $10,035.2$ & 4.5 & 486.69 \\
\hline 7 & 331 & $13,729.8$ & 8.9 & $12,299.0$ & 9.2 & 549.19 \\
\hline 8 & 332 & $12,602.8$ & 5.7 & $10,113.6$ & 6.3 & 504.11 \\
\hline 9 & 333 & $12,014.8$ & 4.4 & $7,379.4$ & 5.2 & 480.59 \\
\hline
\end{tabular}


the deformation changed from $5.5 \mathrm{~mm}$ to $8.8 \mathrm{~mm}$. When the laser incident angle was set at $100^{\circ}$, the deformation of $9.2 \mathrm{~mm}$ was achieved. Interestingly, as the incident angle changed from $80^{\circ}$ to $100^{\circ}$ the ultimate tensile strength was increased by $9.62 \%$ and in contradiction, the deformation was improved by $67 \%$. As shown in Table 4 , it could be observed that at the laser incident angle of $100^{\circ}$, a lesser deviation occurred in the ultimate tensile strength and deformation. From the experimental results, it could be concluded that as the incident angle is increased the strength and deformation of the welded steel also increased.

Table 4. Angle versus tensile strength difference results

\begin{tabular}{ccc}
\hline Serial. No. & Angle $\left[^{\circ}\right]$ & Tensile strength difference [MPa] \\
\hline \multirow{2}{*}{1} & \multirow{2}{*}{80} & 30.57 \\
\cline { 3 - 3 } 2 & \multirow{2}{*}{20} & 17.65 \\
\cline { 3 - 3 } & \multirow{2}{*}{30} & 7.06 \\
\cline { 3 - 3 } & \multirow{2}{*}{100} & 9.41 \\
\hline
\end{tabular}

\subsection{Finite Element Analysis}

The finite element analysis (FEA) is performed using Simufact software and the results show that the failure strength is nearly the same as in the experimental results. For instance, the ultimate strength of sample no 312 is determined to be $487.65 \mathrm{MPa}$; in contrast to the Simufact software analysis, it is revealed to be $485.18 \mathrm{MPa}$. These results clearly illustrate that there is an exceptionally less deviation as in software results with the ideal measured conditions [42] and [43]. Furthermore, the finite element modelling (FEM) was performed using Simufact welding software to understand the temperature-dependent thermophysical and mechanical properties of matter. Fig. 6 illustrates the temperature field in the selected time during the laser beam welding of sample number 312 with a laser power of $2200 \mathrm{~W}$, the velocity of the laser beam is $25 \mathrm{~mm} / \mathrm{s}$, and the laser incident angle is $90^{\circ}$. The fusion zone is very narrow, and the temperature of the base metal distant from the weld centreline remained practically unchanged. Accordingly, the ultimate tensile strength of welded TRIP steel depending on the input parameters and its thermomechanical treatment showed an ultimate strength of $485.18 \mathrm{MPa}$. Due to the effect of the laser power, the temperature is very high, but the is transferred to the atmosphere through conduction, convection, radiation; all of this has to be completed within a split of a second. According to
Fig. 6, the nuclear region is associated with a higher yellow zone, which has a higher temperature than other regions. The free end marked in blue indicates the temperature below the merging zone temperature.

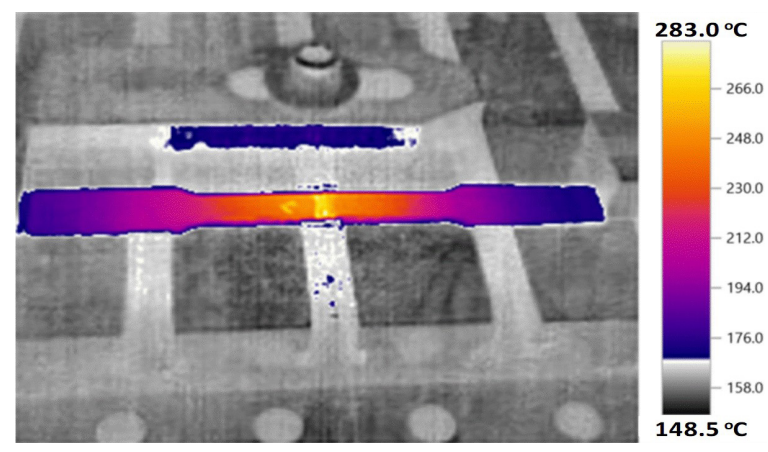

Fig. 6. Thermal image capture for sample no. 312 (Scale: $1 \mathrm{~mm}=20 \mathrm{~mm}$ with actual dimension)

\section{CONCLUSIONS}

In this manuscript, the TRIP steel joints were characterized to understand their microhardness, tensile strength, and deformation, for laser power, laser incident angle, and laser welding velocity. The experimental result with sample no. 312 showed an ultimate strength of $487.65 \mathrm{MPa}$, in contrast to the simulation software, which showed the ultimate strength as $485.18 \mathrm{MPa}$, which is relatively less deviation from the experimental results. Furthermore, from the experimental results, it is clear that the laser incident angle played a substantial role in the enhancement of as-prepared steel strength. The maximum ultimate strength of $549 \mathrm{MPa}$ was observed at an $80^{\circ}$ incident angle with $30 \mathrm{~mm} / \mathrm{s}$ velocity, and $2200 \mathrm{~W}$ power. Also, it could be observed that the deformation value and steel strength had increased as the power and velocity increased. Furthermore, our microstructure study illustrated that the microhardness in the fusion zone was increased to $185 \mathrm{HV} 1.0 / 10$ by increasing the power and keeping the other parameters at a low level.

Nevertheless, by further increasing the power and velocity, the microhardness value could be increased to $195 \mathrm{HV} 1.0 / 10$. Conversely, if the power is kept at the lower side (i.e., $1800 \mathrm{~W}$ ), then the microhardness value dropped to $116 \mathrm{HV} 1.0 / 10$. The finite element modelling showed no cracks or pores, confirming that as-prepared specimens are less thermally deformed. 


\section{ACKNOWLEDGEMENTS}

The authors would like to thank Marathwada Mitra Mandal's College of Engineering (MMCOE) Karvenagar for providing characterization equipment. Dr Puttaswamy Madhusudan would like to acknowledge Ton Duc Thang University, Ho Chi Minh City, Vietnam for their financial support.

\section{REFERENCES}

[1] Rajashekhar, S.S., Molian, P. (2009). Yb:YAG laser welding of TRIP780 steel with dual-phase and mild steels for use in tailor welded blanks. Materials \& Design, vol. 30, no. 10, p. 41464155, D0l:10.1016/j.matdes.2009.04.033.

[2] Wei, H., Zhang, Y., Tan, L., Zhong, Z. (2015). Energy efficiency evaluation of hot-wire laser welding based on process characteristic and power consumption. Journal of Clean Production, vol. 87, p. 255-262, D0l:10.1016/j. jclepro.2014.10.009.

[3] Quazi, M.M., Ishak, M., Fazal, M.A., Arslan, A., Rubaiee, S., Qaban, A., Aiman, M.H., Sultan, T., Ali, M.M., Manladan, S.M. (2020). Current research, and development status of dissimilar materials laser welding of titanium and its alloys. Optics \& Laser Technology, vol. 126, art. ID 106090, D0I:10.1016/j.optlastec.2020.106090.

[4] Aslanlar, S. (2006). The effect of nucleus size on mechanical properties in electrical resistance spot welding of sheets used in automotive industry. Materials \& Design, vol. 27, no. 2, p. 125-131, D0l:10.1016/j.matdes.2004.09.025.

[5] Zhang, X.Q., Chen, G.L., Zhang, Y.L. (2008). Characteristics of electrode wear in resistance spot welding dual-phase steels. Materials \& Design, vol. 29, no. 1, p. 279-283, D0l:10.1016/j. matdes.2006.10.025.

[6] Razmpoosh, M.H., Macwan, A., Biro, E., Zhou, Y. (2020). Microstructure and dynamic tensile characteristics of dissimilar fiber laser welded advanced high strength steels. Materials Science and Engineering: A, vol. 773, art. ID 138729, D0I:10.1016/J.msea.2019.138729.

[7] Vercruysse, F., Castro Cerda, F.M., Verleysen, P., Petrov, R.H. (2020). Behavior of ultrafast annealed advanced high strength steels under static and dynamic conditions. Materials Science and Engineering: A, vol. 780, art. ID 139168, D0l:10.1016/j. msea.2020.139168.

[8] Mahmoudiniya, M., Kokabi, A.H., Goodarzi, M., Kestens, L.A.I. (2020). Friction stir welding of advanced high strength dual phase steel: Microstructure, mechanical properties and fracture behavior. Materials Science and Engineering: $A$, vol. 769, art. ID 38490, D0I:10.1016/j.msea.2019.138490.

[9] Sun, Y.F., Fujii, H., Takaki, N., Okitsu, Y. (2013). Microstructure and mechanical properties of dissimilar Al alloy/steel joints prepared by a flat spot friction stir welding technique. Materials \& Design, vol. 47, p. 350-357, D0l:10.1016/j. matdes.2012.12.007.

[10] Ding, F.X., Lan, L.F., Yu, Y.J., Man, M.K. (2020). Experimental study of the effect of a slow-cooling heat treatment on the mechanical properties of high strength steels. Construction and Building Materials, vol. 241, art. ID 118020, DOI:10.1016/j.conbuildmat.2020.118020.

[11] Saha, D.C., Westerbaan, D., Nayak, S.S., Biro, E., Gerlich, A.P., Zhou, Y. (2014). Microstructure-properties correlation in fiber laser welding of dual-phase and HSLA steels. Materials Science and Engineering: A, vol. 607, p. 445-453, DOI:10.1016/j.msea.2014.04.034.

[12] Xia, M., Biro, E., Tian, Z., Zhou, Y.N. (2008). Effects of heat input and martensite on HAZ softening in laser welding of dual-phase steels. ISIJ International, vol. 48, no. 6, p. 809814, D0I:10.2355/isijinternational.48.809.

[13] Biro, E., McDermid, J.R., Embury, J.D., Zhou, Y. (2010). Softening kinetics in the subcritical heat-affected zone of dualphase steel welds. Metallurgical and Materials Transaction A, vol. 41, p. 2348-2356, D0l:10.1007/s11661-010-0323-2.

[14] Baltazar Hernandez, V.H., Nayak, S.S., Zhou, Y. (2011). Tempering of martensite in dual-phase steels and its effects on softening behavior. Metallurgical and Materials Transaction A, vol. 42, p. 3115-3129, Dol:10.1007/s11661-011-0739-3.

[15] Nayak, S.S., Baltazar Hernandez, V.H., Zhou, Y. (2011). Effect of chemistry on nonisothermal tempering and softening of dual-phase steels. Metallurgical and Materials Transaction A, vol. 42, p. 3242-3248, D0l:10.1007/s11661-011-0868-8.

[16] Biro, E., Vignier, S., Kaczynski, C., Mcdermid, J.R., Lucas, E., Embury, J.D., Zhou, Y.N. (2013). Predicting transient softening in the sub-critical heat-affected zone of dual-phase and martensitic steel welds. ISIJ International, vol. 53, no. 1, p. 110-118, Dol:10.2355/isijinternational.53.110.

[17] Zhao, L., Wibowo, M.K., Hermans, M.J.M., van Bohemen, S.M.C., Sietsma, J. (2009). Retention of austenite in the welded microstructure of a $0.16 \mathrm{C}-1.6 \mathrm{Mn}-1.5 \mathrm{Si}$ (wt\%) TRIP steel. Journal of Materials Processing Technology, vol. 209, no. 12-13, p. 5286-5292, D0I:10.1016/J.jmatprotec.2009.03.017.

[18] Xia, M., Tian, Z., Zhao, L., Zhou, Y.N. (2008). Metallurgical and mechanical properties of fusion zones of TRIP steels in laser welding. ISIJ International, vol. 48, no. 4, p. 483-488, DOI:10.1016/J.jmatprotec.2009.03.017.

[19] Jeon, W.S., Sharma, A., Jung, J.P. (2020). Liquid metal embrittlement of galvanized TRIP steels in resistance spot welding. Metals, vol. 10, no. 6, art. ID 787, D0l:10.3390/ met10060787.

[20] Gonçalves, T.S., de Faria, G.L., de Siqueira, R.H.M., de Lima, M.S.F. (2020). Weldability and mechanical behavior of laserwelded TRIP 750 steel sheets. International Journal of Advanced Manufacturing Technology, vol. 107 p. 2807-2815, DOI:10.1007/s00170-020-05223-y.

[21] Polatidis, E., Čapek, J., Arabi-Hashemi, A., Leinenbach, C., Strobl, M. (2020). High ductility and transformation-inducedplasticity in metastable stainless steel processed by selective laser melting with low power. Scripta Materialia, vol. 176, p. 53-57, D0I:10.1016/j.scriptamat.2019.09.035.

[22] Wang, X.H., Kang, J., Li, Y.J., Yuan, G., Misra, R.D.K., Wang, G.D. (2020). Characterisation on Al-bearing hot-rolled TRIP steel produced through isothermal bainite transformation. Materials Science and Technology, vol. 36, no. 2, p. 210-222, DOI:10.1080/02670836.2019.1695079.

[23] Atílio, I., Braga, V., de Siqueira, R.H.M., de Carvalho, S.M., de Lima, M.S.F. (2020). Comparing the weldability of AA60013-T4 
aluminum alloy on DP600 dual-phase steel with laser welding and resistance spot welding. Journal of Brazilian Society of Mechanical Science and Engineering, vol. 42, art. ID 71, DOI:10.1007/s40430-019-2158-0.

[24] Pastor, M., Zhao, H., Martukanitz, R.P., Debroy, T. (1999). Porosity, underfill and magnesium loss during continuouswave $\mathrm{Nd}$ :YAG laser welding of thin plates of aluminum alloys 5182 and 5754. Welding Journal, vol. 78, p. 207s-216s.

[25] Haboudou, A., Peyre, P., Vannes, A.B., Peix, G. (2003). Reduction of porosity content generated during $\mathrm{Nd}$ :YAG laser welding of A356 and AA5083 aluminum alloys. Materials Science and Engineering A, vol. 363, no. 1-2, p. 40-52, Dol:10.1016/S0921-5093(03)00637-3.

[26] Sun, Z., Ion, J.C. (1995). Laser welding of dissimilar metal combinations. Journal of Materials Science, vol. 30, p. 42054214, D0I:10.1007/BF00361499.

[27] Hoffmann, P., Geiger, Geiger, M. (1995). Recent developments in laser system technology for welding applications. CIRP Annals, vol. 44, no. 1, p. 151-156, D0l:10.1016/S00078506(07)62295-1.

[28] Yang, Z.B., Tao, W., Li, L.Q., Chen, Y.B., Li, F.Z., Zhang, Y.L. (2012). Double-sided laser beam welded T-joints for aluminum aircraft fuselage panels: process, microstructure, and mechanical properties. Materials Design, vol. 33, p. 652-658, D0l:10.1016/j.matdes.2011.07.059.

[29] Farrokhi, F., Nielsen, S.E., Schmidt, R.H., Pedersen, S.S., Kristiansen, M. (2015). Effect of cut quality on hybrid laser arc welding of thick section steels. Physics Procedia, vol. 78, p. 65-73, D0l:10.1016/j.phpro.2015.11.018.

[30] Rizzi, P., Bellingeri, S., Massimino, F., Baldissin, D., Battezzati, L. (2009). Microstructures in laser welded high strength steels. Journal of Physics: Conference Series, vol. 144, p. 1-4, DOI:10.1088/1742-6596/144/1/012005.

[31] Li, W., Ma, L., Peng, P., Jia, Q., Wan, Z., Zhu, Y., Guo, W. (2018). Microstructural evolution and deformation behavior of fiber laser welded QP980 steel joint. Materials Science Engineering: A, vol. 717, p. 124-133, Dol:10.1016/j.msea.2018.01.050.

[32] Mujica, L., Weber, S., Pinto, H., Thomy, C., Vollertsen, F. (2010). Microstructure and mechanical properties of laser welded joints of TWIP and TRIP steels. Materials Science Engineering A, vol. 527, no. 7-8, p. 2071-2078, D0l:10.1016/j. msea.2009.11.050.

[33] Atabaki, M.M., Yazdian, N., Ma, J., Kovacevic, R. (2016). High power laser welding of thick steel plates in a horizontal butt joint configuration. Optics \& Laser Technology, vol. 83, p. 1-12, D0l:10.1016/J.optlastec.2016.03.016.
[34] Li, M., Wu, R.H., Cai, S., Chang, Z.D., Wang, Z.H., Chen, J. (2020). Experimental investigation on friction-stir-assisted incremental forming with synchronous bonding of aluminum alloy and steel sheets. Journal of Materials Engineering and Performance, vol. 29, p. 750-759, D0l:10.1007/s11665-02004600-8.

[35] Mazar Atabaki, M., Ma, J., Yang, G., Kovacevic, R. (2014). Hybrid laser/arc welding of advanced high strength steel in different butt joint configurations. Materials Design, vol. 64, p. 573-587, D0I:10.1016/j.matdes.2014.08.011.

[36] Speer, J., Matlock, D. K., Cooman, B.C.D., Schroth, J.G. (2003). Carbon partitioning into austenite after martensite transformation. Acta Materialia, vol. 51, no. 9, p. 2611-2622, D0I:10.1016/S1359-6454(03)00059-4.

[37] Hajyakbary, F., Sietsma, J., Miyamoto, G., Kamikawa, N., Petrov, R.H., Furuhara, T., Santofimia, M.J. (2016). Analysis of the mechanical behavior of a $0.3 \mathrm{C}-1.6 \mathrm{Si}-3.5 \mathrm{Mn}$ (wt.\%) quenching and partitioning steel. Materials Science Engineering A, vol. 677, p. 505-514, D0I:10.1016/j.msea.2016.09.087.

[38] Khot Rahul, S., Venkateswara Rao, T. (2020). Effect of quenching media on laser butt welded joint on transformedinduced plasticity (TRIP) steel. International Journal of Advanced Trends in Computer Science and Engineering, vol. 9, no. 5, p. 7544-7549, DOl:10.30534/ijatcse/2020/90952020.

[39] Khot Rahul, S., Venkateswara Rao, T. (2020). Investigation of mechanical behaviour of laser welded butt joint of transformed induced plasticity (TRIP) steel with effect laser incident angle. International Journal of Engineering Research and Technology, vol. 13, no. 11, p. 3398-3403, D0l:10.37624/ IJERT/13.11.2020.3398-3403.

[40] ASTM International, (2009). Standard Test Methods for Tension Testing of Metallic Materials. ASTM International. ASTM E8, p. 1-27.

[41] Khot Rahul, S., Rao, T.V., Keskar, A., Girish, H.N., Madhusudan, P. (2020). Investigation on the effect of power and velocity of laser beam welding on the butt weld joint on TRIP steel. Journal of Laser Application, vol. 32, no. 1, art. ID 012016, DOI:10.2351/1.5133158.

[42] Santofimia, M.J., Zhao, L., Sietsma, J. (2009). Microstructural evolution of low-carbon steel during application of quenching and partitioning heat treatments after partial austenitization. Metallurgical and Materials Transaction A, vol. 40, p. 46, DOI:10.1007/s11661-008-9701-4.

[43] Anawa, E.M., Olabi, A.G. (2008). Optimization of tensile strength of ferritic/austenitic laser-welded components. Optics and Laser in Engineering, vol. 46, no. 8, p. 571-577, DOl:10.1016/J.optlaseng.2008.04.014. 